\title{
INTERPRETATION OF GEOPHYSICAL SURVEYS
}

$\mathrm{R}^{\mathrm{B}}$ ECENT improvements in geophysical instruments have not simplified interpretation of the data obtained by using them. Indeed, their greater speed and higher accuracy inorease the data to be analysed and foster attempts to interpret in finer detail. Assessment of factors controlling the reasonable limits of interpretation was the main aim of a Geophysical Discussion of the Royal Astronomical Society, held in association with, and at the rooms of, the Geological Society on October 27. Introducing the four invited speakers, the chairman, Dr. W. Bullerwell (Geological Survey), remarked that geophysical interpretation is usually tested by subsequent geological exploration; thus it was appropriate that discussion about interpretation should take place among geologists and benefit from their comment.

In opening the discussion, Prof. J. M. Bruckshaw (Imperial College of Science and Technology, London) reviewed the treatment of gravity and magnetic survey data, where interpretations aim to deduce sub-surface mass distributions accounting for observed surface fields. Fundamental difficulties are ambiguity and lack of resolution. Ambiguity reflects dependence of the gravity anomaly on several factors, including form, size, depth and density contrast. When all these factors concerning a buried mass are known, it is possible to predict uniquely the effect on gravity at any point on the surface; but when interpreting a gravity profile recorded in a new area, the factors cannot be evaluated individually, and possible permutations allow many solutions consistent with the profile. Only geological control can limit the inherent ambiguities. Lack of resolution was illustrated by indicating that the interpreter cannot distinguish a point mass from a cube or sphere, since all produce similar gravity profiles. Depth to centre, howover, can be computed with reasonable accuracy and an estimate of size is obtainable from the maximum of the anomaly, though it depends in turn on an estimate of density contrast.

Various numerical methods of analysis have been proposed, but Prof. Bruckshaw stressed that mathematical transformations cannot overcome limitations inherent in the original data, while subjective bias may be introduced in the process. As a preliminary step, it is usual to isolate local anomalies thought to represent shallow geological structures by removing a regional background corresponding to smooth average variations. Only rarely, however, can the regional be assigned geological significance, and the smoothed form assumed varies between different interpreters. Attention has been given to the second vertical derivative of gravity following claims of higher resolution from a fourth-power relation with depth as compared with the normal square law, and correspondence between zero contours of second derivative and vertical density boundaries. Unfortunately, precise evaluation of second derivatives requires continuous information whereas field observations are made at a series of discrete points. One process of analysis depends on the subjective drawing of smooth curves through available points. Alternatively, an interpolation formula may be applied, but developed formulæ give different solutions depending on size and form of primary grid. Final stages depend on comparisons with model curves, and it is important to derive these using the same grid. In reconnaissance of new areas, such methods are rarely warranted. No amount of mathematical analysis can remedy insufficient geological control, and if only geophysical data are available, interpretation always remains ambiguous. This was demonstrated recently in an example published by P. E. Jacobsen, of the Creole Petroleum Co., showing differences between two independent interpretations of a magnetic survey in eastern Venezuela. However, if good geological control is available and physical properties of the geological formations have been extensively studied, as in parts of England, some difficulties can be resolved and confident estimates advariced.

Dr. M. H. P. Bott (University of Durham) agreed that gravity and magnetic data are ambiguous, but felt that useful conclusions can generally be salvaged from the sea of uncertainty by applying simplifying assumptions legitimately drawn from geological knowledge of similar environments. The proctical limit of interpretation is frequently determined by how far such reasonable assumptions permit assessment of background and isolation of the interesting anomaly from other disturbances. Once the anomaly has been isolated, total mass can be accurately evaluated by areal integration of the gravity contours. Russian work, recently developed further by Dr. R. A. Smith, shows that if only a few conditions are satisfied a unique solution may be possible. As an example, if an anomaly arises at a single interface across which the density contrast is constant and known, then the shape of the interface can be intespreted directly. Usually the limiting conditions are not accurately known but can be expected to lie within a certain range, and this information permits use of an uncertainty principle through the inequality theorems of Bullard and Cooper, later extended by Bott and Smith. Minimum and maximum values for depth to the source of the anomaly can be obtained. Limiting depth estimates can be derived also from second and third horizontal derivatives of the gravity anomaly, through formulæ of Dr. R. A. Smith relating maximum derivative and maximum depth. The limiting case, corresponding to a symmetrical truncated wedge-shaped body with each edge contributing equally to the derivative, can be modified for the situation where one edge is distant from the point of observation, as for measurements at the margin of an extensive body. Dr. Bott showed how, using this method, he had analysed profiles across the margin of the Weardale anomaly for an estimate of depth to the top surface of the postulated Weardale granite, afterwards proved (at a depth of $1,281 \mathrm{ft}$.) in a deep borehole at Rookhope, Co. Durham. Using maxima in second and third horizontal derivatives calculated from closely spaced observations by gravity meter and assuming density contrast of $0.2 \mathrm{gm} . / \mathrm{cm} .{ }^{3}$, analysis had shown that the top of the postulated granite must lie at less than $3,500 \mathrm{ft}$. beneath Weardale. It is difficult to measure gradient maxima sufficiently accurately with a gravity meter, since an average over a base-line and not a point-value is 
observed. Dr. Bott believes that the torsion-balance, little used recently, might be used advantageously.

Similar methods often prove satisfactory for decid. ing between alternative geological possibilities, as in distinguishing gravity lows over sedimentary basins from those due to granites. In the former case the boundaries of the lighter sediments slope in towards the centre of the anomaly, whereas the granite margins slope out at depth. Different amplitude ratios between derivative maximum and minimum flanking tho anomaly are detectable, and contrasting results from gravity traverses crossing the margins of the Cheshire Basin and the Dartmoor Granite were displayed. Finally, useful results can be derived from comparisons with models, since modern digital computers will check quite speedily whether a postulated geological structure would produce the profile observed or whether marked divergences necessitate a new hypothesis. Dr. Bott concluded by saying that, applied to analyse magnetic data, these methods encounter added difficulties due to variations in direction of permanent magnetization.

Mr. G. Tait (Iraq Petroleum Co.) contributed a paper outlining the geophysicist's views on interpretation of seismic surveys. He remarked that recent instrumental developments aim at producing a greatly simplified presentation of results in the hope that by transforming a series of impulses into a variable density profile the main features of the geological structure may be comprehended at a glance. No method of presentation, however, alters the fact that the behaviour of the seismic wave depends on elastic constants in the rock formations concerned, and progress or difficulties in interpretation relate to whether and where variations in these constants occur. It is not always possible to predict from lithology, for seismic velocities in adjacent sandstones and limestones can be identical. Local velocity control is doubly important, because velocity discontinuities may not correlate directly with stratigraphic interfaces and because travel-time and velocity have equal weight in seismic determination of depth. Satisfactory velocity data can be obtained from well shooting or by recording velocity logs in deep boreholes; but in virgin areas, where information must come from surface shots, available values may be inadequate. Accurate velocities can help when distinguishing between multiple reflexions and deep reflectors from curvatures in the moveout or by recognizing anomalous dips.

Several of these and other complications which the interpreter must disentangle were clearly demonstrated from oil exploration surveys by the Iraq Petroleum Co. One slide showed how tangential distortion against high-speed beds can simulate the indications of a natural structure. Importance of spread-length was apparent in the same example, since curvatures which could not be identified on a short spread becamo clearly visible at $12,000 \mathrm{ft}$. Records of a noise-spread indicated that alignments in background may confuse with weak reflexions. Profiles shot in the foothills of Iraq demonstrated both the problems and the importance of identifying multiple reflexions and diffraction cross-overs which may have amplitudes greater than those of the geologically significant events. Lower-amplitude contrast between events in a profile across the main producing oilfield of Iraq made it appear somewhat of an anticlimax, though containing important informa. tion. Mr. Tait's evidence made clear that, in dealing with seismic records, the interpreter must continuously bear in mind natural conditions under which the survey has been performed, velocity data available, instrument lay-out and complications which may have confused the records with multiple reflexions and diffraction effects.

Mr. A. N. Thomas (British Petroleum Co.) discus sing geological factors in the planning and interpreta. tion of seismic surveys, stressed the need for close co-ordination of geological and geophysical information. His first example, taken from the Po Valley, showed seismic reflexions on a phantom horizon to which geological information had been added, seismic evidence controlling the section as to fault zones and dips, while stratigraphical detail came from boreholes. Following examples came from southwest Iran, where initial interpretation difficulties with seismic refraction surveys were resolved when stratigraphical considerations correlated highest velocity with Middle Cretaceous Rudist limestone, not with the massive Asmari limestone 2,000-3,000 ft. above. Refraction arcs in the Lali Plain, starting from positions determined by surface geological mapping, directed attention progressively southwards to prove concealed Asmari limestone structures. In other British Petroleum Co. surveys across Agha Jari and Lali, surface dip observations by geologists in an area of disharmonic folding gave valuable checks on geophysical evidence about elevation of a concealed crest. In exchange, structural interpretation of the surface geological maps was aided by the geophysical information. Evidence from Iran showed that, by producing regional isopach and facies maps, the geologist can illuminate seismic interpretation wherever such variations control velocity or ability to act as a refractor.

The bearing of velocity anomalies on seismic interpretation was next considered using an example by D. C. Skeels from a Devonian reef oilfield in West Canada. Reflexion times at boreholes to the Lower Cretaceous gave a velocity map used for controlling the seismic data, and the final seismic depth-map agreed with later sub-surface information more closely than an earlier map based on reflexion times only. In more complicated conditions accompanying Reef limestones in Western Alberta, structure contour maps and seismic isochron maps may show different relationships on successive horizons. Causes are sometimes difficult to assess, but it is clear that seismic evidence must be checked against drilling data at all available positions and levels. Difficulties in correlating reflexion pulses with specific geological formations were illustrated in results obtained near Calgary by Dr. T. C. Richards, in which corresponding seismic peaks and troughs could be seen to change stratigraphic horizon in different parts of the area. The sections also showed how ideas about the structure of the area changed as various stages of drilling, seismic survey and further drilling were completed. This analysis indicated the tendency of the seismic interpretation to smooth out complications and inability to locate with certainty the top of the Palæozoic, which is the most important lithological break.

Mr. Thomas concluded by saying that too much should not be expected from a seismic survey. It cannot eliminate the need for sound geological investigation; both lines of approach are necessary. The seismic method cannot give a complete picture of sub-surface conditions in areas of complicated structure, and geologists should realize the limitations imposed by the nature of the method. 
Opening the meeting for general diseussion, Dr. Bullerwell recalled a remark of Prof. Bruckshaw that potential theory has been known a very long time and that in many fields interpretation shows no fundamental advance over the past fifteen years. Noting that during this period there has been increased use of systems like the airborne magnetometer for recording continuous profiles, he asked whether these removed some of the subjective elements mentioned. Prof. Bruckshaw replied that the subjective element, remains in spite of such developments, due to the gaps between profiles and uncertainties in completing contours. Though coverage is improved, it is never complete. Dr. W. Domzalski felt that some views expressed had been unduly pessimistic. Even though interpretations might prove quantitatively in error, qualitative results obtained following an imaginative approach often lead to new discoveries. For reasonable success in interpretation it is also important to choose the geophysical method most suited to the geological problem. Even where no control information to guide the interpretation is available, the possible results may justify geophysical work as the most economical means of preliminary reconnaissance. On the question of economics, Dr. Bullerwell asked how soon during a survey should the results be tested by drilling. Mr. N. I.. Falcon said that satisfactory exploration implies a balanced programme combining geology, geophysics and drilling. It is desirable to establish control, pursue the investigation comprehensively and not anticipate conclusions on the basis of too few results, but geophysical interpretation remains speculative until the key localities are drilled. Dr. T. C. Richards said that geophysical experiences in Canada emphasize the importance of early dilling control. A quantitative approach is essential throughout and second-derivative gravity maps have proved unreliable for this. Seismic methods must be intro. duced at a very early stage and have adequate geological and drilling control, especially in the Reef field, to overcome difficulties due to facies changes. Otherwise, occurrences of Reef limestone in limestone or local velocity anomalies, as at Swan Hills, Alberta, would not be recognized.

In closing the meeting the chairman remarked that personal experience often decides for one interpretation method rather than another. Perhaps a real advance during the past fifteen years is represented by pooling of experience through free discussion and improved publication of geophysical results. There is certainly a clear recognition of fundamental problems.

\section{TWELFTH INTERNATIONAL ASTRONAUTICAL CONGRESS}

$\mathrm{T}$ HE International Astronautical Congress is an annual meeting of the interplanetary societies of the world. Societies take it in turn to act as host, and the recent meeting, during October 1-7, in Washington, was the first occasion that the meeting had been held on the American continent. Next year's conference was fixed for Sofia, Bulgaria, it having been held in Stockholm last year and London in 1959. Of the 750 people registered, some 300 came from outside the United States. The president of the International Astronautical Congress this year was Academician L. I. Sedov, of the U.S.S.R., and for the forthcoming year Prof. J. Pérès, of France, was appointed the new president.

The week following the Congress was the occasion of a meeting in New York by the American Rocket Society - "Spaceflight Report to the Nation".

There was perhaps a feeling that the International Astronautical Congress was of not quite such a high technical standard as previous ones, as many Americans seemed to consider the American Rocket Society meeting to be the more important of the two-a view not altogether shared by the European delegates.

The opening ceremony on Monday was followed by a reception and buffet at the Bolling Air Force Base, where Dr. Theodore von Kármán was very much in evidence among the delegates.

The technical sessions started at 9 a.m. on October, 3 with three simultaneous sessions on space propulsion, astrodynamics and guidance, and the Fourth Colloquium on the Law of Outer Space (the Third Colloquium was held in Stockholm in 1960).

The session on space propulsion had two lectures from British delegates, the first by Mr. A. W. T. Mottram (Bristol Siddeley Engines, Ltd., Coventry) entitled: "Propulsion of the Final Stage of a Satellite Launcher using Liquid Hydrogen as Fuel". Although this was the first lecture of the morning, it was well attended and there was a good discussion, although
Americans in the audience were perhaps a little reluctant to describe some of their more recent failures in this field. It must be remembered that liquid hydrogen has not yet been used successfully to place a satellite in orbit, and that it was announced during the course of the Congress that the Centaur rocket using liquid hydrogen as a fuel has been officially set back eight months.

The other British paper, "An Examination of the Characteristics of Propulsion Systems for InterOrbital Transfer", by P. A. E. Stewart (Hawker Siddeley Aviation) was read in his absence by his colleague, Dr. W. F. Hilton. This described the more exotic forms of propulsion, including an omnidirectional method of focusing the Sun's rays for the direct heating of liquid hydrogen for use as a working substance.

Undoubtedly the most noteworthy paper of the morning was by another British delegate, Arthur C. Clarke (Clarke-Wilson Associates, Colombo), under the title "The Social Impact of Communications Satellites". This was presented during the Space Law Colloquium and attracted widespread interest. A future state of affairs where worldwide communications are as cheap and reliable as our present local communications was investigated, and its effects on social behaviour and trade were discussed. $\mathrm{Mr}$. Clarke is, of course, well known for having started the idea of communications satellites by his article in October 1945 in The Wireless World, and indeed a reprint of this article wes issued to all delegates.

The Space Law Colloquium continued in the afternoon and there was a session on energy conversion and yet another simultaneous session on astrodynamics and guidance. This last subject was treated as a round-table topic where a number of contributors made both prepared and unprepared comments, and included Prof. Zdenek Kopal (University of Manchester). 